\title{
Bilateral Abducens Nerve Palsy and the possible Association with COVID-19: A Case Report
}

\author{
Abdulla Abu Hantash', Mohammed Abu Safieh², Salam Iriqat ${ }^{3 *}$, Mohammad Daraghmeh ${ }^{4}$ \\ ${ }^{1}$ Head of cornea and anterior segment department, St John Eye Hospital, East Jerusalem, Palestine \\ ${ }^{2} 4$ th year ophthalmic resident, St John Eye Hospital, East Jerusalem, Palestine. \\ ${ }^{3}$ Ocular Inflammatory Disease Department, St John Eye Hospital, East Jerusalem, Palestine. \\ ${ }^{4}$ Pediatric and neuro-ophthalmology senior specialist, St John Eye Hospital, East Jerusalem, Palestine.
}

*Corresponding author: Salam Iriqat, Ocular Inflammatory Disease Department, St John Eye Hospital, East Jerusalem, Palestine.

Received date: August 11, 2021; Accepted date: August 24, 2021; Published date: August 30,2021

Citation: Abdulla Abu Hantash, Mohammed Abu Safieh, Salam Iriqat, Mohammad Daraghmeh (2021) Bilateral Abducens Nerve Palsy and the possible Association with COVID-19: A Case Report. J. Archives of Medical Case Reports and Case Study, 4(4); DOI:10.31579/2692-9392/078

Copyright: () 2021 Majdi Gueldich, This is an open access article distributed under the Creative Commons Attribution License, which permits unrestricted use, distribution, and reproduction in any medium, provided the original work is properly cited.

\begin{abstract}
Cranial nerve neuropathy could be a part of neurological spectrum of COVID-19 disease. Research suggests SARSCoV-2 infection can trigger an aberrant immune response in some individuals, causing inflammatory nerve damage leading to anosmia and neuropathy. We report here a 50-year-old female patient who presented to the outpatient clinic in Saint John Eye Hospital with a two months history of binocular, horizontal diplopia five days after recovery from SARS-CoV-2 infection, PCR positive test obtained by a nasopharyngeal swab on April 1st, 2021 with upper respiratory tract symptoms. The patient was diagnosed with bilateral abducens nerve palsy. The main cause was presumed to be post-viral as the patient had controlled diabetes "HBA1C: 7\%" and had no pre-existing microvascular risk factors. Diplopia still exists after two months of bilateral abducens nerve palsy. Measurements confirmed bilateral limited abductions in both eyes with right or alternating convergent squint.

This case report supports the hypothesis that direct or indirect virally mediated injuries along the routes of the cranial nerves can cause neuropathy and olfactory dysfunction. The longer latency effects of COVID-19 infection are not well understood. This case report aims to raise awareness amongst clinicians of coronavirus-induced neurological symptoms

Key words: SARS-CoV-2; COVID-19
\end{abstract}

\section{Introduction}

The COVID-19 disease emerged in Wuhan province of China in November 2019 and spread across the world in a short time, resulting in a pandemic. The first five cases in Palestine were detected on March 5, 2020. Since then, the disease has continued to spread rapidly, and the number of cases has increased in all provinces. Coronaviruses are a large family of viruses that are seen as the causative agent of a wide range of clinical symptoms from the common cold to severe pneumonia, such as Middle East Respiratory Syndrome (MERS-CoV) and severe acute respiratory syndrome (SARS$\mathrm{CoV})$. SARS-CoV2, responsible for the COVID-19 disease, is considered to be the most effective of this family of viruses, which has led to the ongoing pandemic. [1]

The incubation period of COVID-19 is around five days in the initial stage of the disease, and although the most common complaints are fever, cough, myalgia, headache, and joint pain, patients can also present with many different symptoms, including taste and smell disorders, diarrhea, and weakness. [2]
The COVID-19 disease caused by the SARS-CoV2 virus commonly results in cranial nerve symptoms. The fact that these findings are more common and severe in COVID-19 than previous SARS and MERS outbreaks suggests that it has a more neurotrophic and more aggressive neuroinvasion. [2]

In this context, we aimed to discuss a case report of acute isolated bilateral abducens nerve palsy following SARS-CoV-2 infection. All patients gave informed consent for the publication of their case details and any accompanying images.

\section{Case Report}

On April $1^{\text {st }} 2021$, a 50-year-old female developed acute upper respiratory tract symptoms "chest pain, dyspnea", with positive PCR test of SARS-CoV2 infection. The symptoms lasted for 14 days then PCR was repeated and returned back negative. Five days after recovery our patient developed binocular, horizontal diplopia and right eye lid retraction.

She was seen at Saint John Eye Hospital two months later. A non-smoker with controlled Diabetes mellitus "HBA1C:7\%", on oral systemic tablet 
JANUMET 50/1000mg once a day. She reported no history of childhood strabismus.

The patient reported headache and fatigue from intermittent diplopia. Thyroid function tests and blood tests were performed with normal range results. MRI was obtained with normal findings. The patient was reviewed by the Orthoptist. Ocular motility examination and Hess chart "Figure 1' revealed a confirmed bilateral limited abductions in both eyes with right or alternating convergent squint.

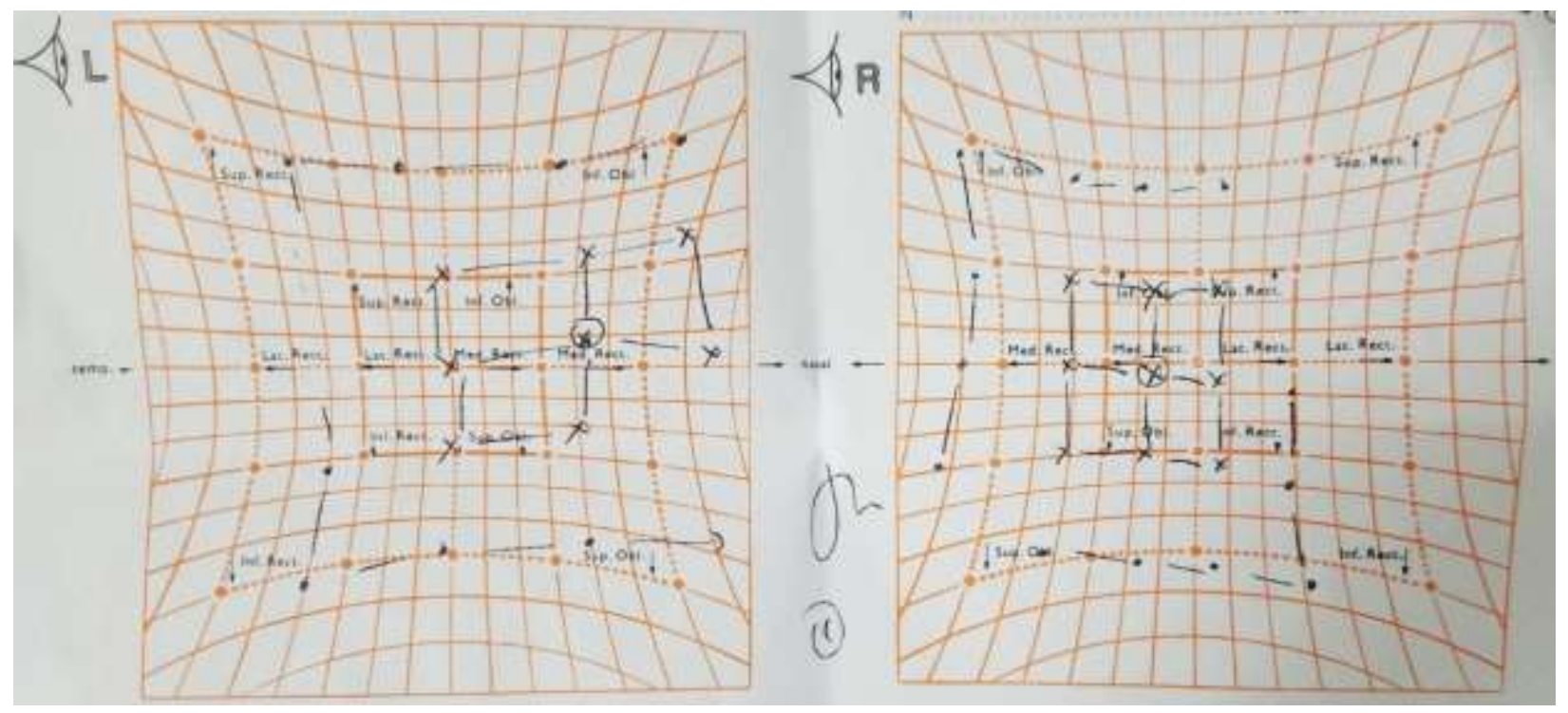

Figure 1: Hess chart of 50 years old female patient with bilateral $6^{\text {th }}$ nerve palsy

The patient showed abnormal head posture with slight face turn to the right side with slight chin up, both eyelids were slightly retracted. The cover test showed right alternating convergent squint measuring 16 prism diopter for near and 25 prism diopters for distance without glasses and 12 prism diopters for near and 14 prism diopters for distance with glasses, ocular movement showed bilateral limitation of abduction with overacting medial rectus bilaterally noticed more in the left eye. Stereopsis is normal.

These findings are consistent with bilateral abducens nerve palsy. Her best corrected visual acuity was normal; it measured $0.00(6 / 6)$ in the right eye and $0.00(6 / 6)$ in the left eye on the ETDRS (Early Treatment Diabetic Retinopathy Study) chart at $4 \mathrm{~m}$. Pupils were equal and reactive to light. There was no afferent pupillary defect. A base out Fresnel prism to relieve diplopia was deferred to next visit because she tolerated her intermittent diplopia. The patient was also reviewed by a neuro-ophthalmologist at Saint John eye hospital.

\section{Discussion}

Abducens nerve palsy is the most common isolated ocular motor palsy and has a wide range of potential aetiologies. [3] It is a rare presentation in younger adults, where the etiology includes vasculopathies, neoplasia, multiple sclerosis and other inflammatory diseases, with viral etiologies responsible for $1-10 \%$ of cases. [4] Clinical presentation manifests as horizontal diplopia, limitation of abduction and an eso-deviation in primary position, measuring greater for distance than close proximity. The association between viral infection and cranial neuropathy is well reported in the literature. [5] In particular, abducens nerve involvement has been linked with confirmed viral infections caused by: Cytomegalovirus, EpsteinBarr virus, Herpes Zoster, Lyme Disease, Measles, Dengue Fever and Scrub Typhus. $[6,7,8,9,10]$ In the literature we found most cases of Abducens nerve palsy were unilateral as in case report of Greer et al. [11] while in our case the patient had bilateral Abducens nerve palsy which should rise our concern of bilateral COVID-19 related neuropathy. Virus mediated immune response. Aberrant immune response may induce neurological injury from pro-inflammatory cytokines. [12,13] Specifically, COVID-19 may infect endothelial cells, compromising the integrity of the blood-brain barrier, or infiltrate leukocytes that become subsequent viral reservoirs for dissemination. [14] Macrophages expressing ACE2 receptors may augment systemic inflammation, perpetuating widespread tissue injury. [15]

The pathogenesis of ophthalmoplegia is controversial and several mechanisms have been postulated: The first is a direct cytopathic effect from the virus itself on the surrounding neural tissue. The second is an immune response of the central nervous system to the virus. The third attributes it to an occlusive vasculitis induced by the virus. A fourth theory suggests that the VZV activates another latent neuropathic virus within the brain. [16]

The Hess Chart can give a good indication of whether a deviation is neurological or mechanical; however, it must not be taken in isolation and should be considered with the rest of the orthoptic report. So, we depend on diagnosis of bilateral abducens nerve palsy on Hess Chart in addition to orthoptic assessment.

\section{Limitations}

The major limiting factor of our study is that we did not have any evidence (such as pathological examination or nerve biopsy sample) to show the direct damage of the virus on the nerves. We cannot go beyond predicting whether this damage occurs as a result of the direct effect of the virus or the development of an immune response-mediated mechanism.

The second limitation is the time that is required to observe the patient for a period to assess how long cranial nerve palsy could last post COVID-19 infection.

Third limitation is that few cases have been published discussing the clinical manifestations of COVID-19 on the eyes. [17] 


\section{Conclusion}

The long latency effects, neurological manifestations, infection pathways and mechanisms of COVID-19 are currently not well understood. This infection mechanism could affect other cranial nerves and produce isolated nerve palsies. Further case reports are necessary to reveal the full spectrum of clinical manifestations of COVID-19 infection.

\section{Acknowledgments:}

The authors thank the patients who agreed to participate in this report.

Disclosure:

The authors declare no conflicts of interest, no financial support for this work.

\section{References:}

1. Ludwig S, Zarbock A. Coronaviruses and SARS-CoV-2: A Brief Overview. Anesth Analg. 2020;131(1):93-96.

2. Doblan, A., Kaplama, M. E., Ak, S., Basmac1, N., Tarini, E. Z., Göktaş, Ş. E., Güler, S., \& Müderris, T. (2021). Cranial nerve involvement in COVID-19. American journal of otolaryngology, 42(5), 102999. Advance online publication.

3. Werner D.B. Benign recurrent sixth nerve palsies in childhood. Arch Ophthalmol. 1983;101(4):607. doi: 10.1001/archopht.1983.01040010607016

4. Peters G.B., Bakri S.J., Krohel G.B. Cause and prognosis of nontraumatic sixth nerve palsies in young adults. Ophthalmology [Internet]. 2002;109(10):1925-1928

5. Guerrero, J.I., Barragán, L.A., Martínez, J.D. et al. Central and peripheral nervous system involvement by COVID-19: a systematic review of the pathophysiology, clinical manifestations, neuropathology, neuroimaging, electrophysiology, and cerebrospinal fluid findings. BMC Infect Dis 21, 515 (2021).

6. Bhardwaj, B, Panda, P, Revannasiddaiah, S and Bhardwaj, H. 2013. Abducens nerve palsy in a patient with scrub typhus: A case report. Tropical Biomedicine, 30: 706-709.

7. Greco, F, Garozzo, R and Sorge, G. 2006. Isolated Abducens Nerve Palsy Complicating Cytomegalovirus Infection. Pediatric Neurology, 35: 229-230. DOI: 10.1016/j.pediatrneurol.2006.03.008
8. Shin, M, Choi, C and Lee, M. 2007. A case of herpes zoster with abducens palsy. Journal of Korean Medical Science, 22: 905-907. DOI: 10.3346/jkms.2007.22.5.905

9. Shivanthan, M, Ratnayake, E, Wijesiriwardena, B, Somaratna, K and Gamagedara, L. 2012. Paralytic squint due to abducens nerve palsy: A rare consequence of dengue fever. BMC Infectious Diseases, 12: 156. DOI: 10.1186/1471-2334-12-156

10. Werner, D, Savino, P and Schatz, N. 1983. Benign recurrent sixth nerve palsies in childhood: Secondary to immunization or viral illness. Archives of Ophthalmology, 101: 607-608. DOI: 10.1001/archopht.1983.01040010607016

11. Greer, Christine E. MD, MS; Bhatt, Jaydeep M. MD; Oliveira, Cristiano A.; Dinkin, Marc J. MD Isolated Cranial Nerve 6 Palsy in 6 Patients With COVID-19 Infection, Journal of Neuro-Ophthalmology: December 2020 - Volume 40 - Issue 4 - p 520-522 doi: 10.1097/WNO.0000000000001146

12. Gutiérrez-Ortiz, C, Méndez, A, Rodrigo-Rey, S, San PedroMurillo, E, Bermejo-Guerrero, L, Gordo-Mañas, R, de Aragón-Gómez, F and Benito-León, J. 2020. Miller Fisher Syndrome and polyneuritis cranialis in COVID-19. Neurology. DOI: 10.1212/WNL.0000000000009619

13. Wang, H, Zhou, M, Brand, J and Huang, L. 2009. Inflammation and taste disorders. Annals of the New York Academy of Sciences, 11701: 596-603. DOI: 10.1111/j.1749-6632.2009.04480.x

14. Francis, J. E. (2021). Abducens palsy and anosmia associated with COVID-19: A case report. British and Irish Orthoptic Journal, 17, 8-12.

15. Dalakas MC. Pathogenesis of immune-mediated neuropathies. Biochim Biophys Acta 2015;1852:658-666.

16. Chaker, N., Bouladi, M., Chebil, A., Jemmeli, M., Mghaieth, F., \& El Matri, L. (2014). Herpes zoster ophthalmicus associated with abducens palsy. Journal of neurosciences in rural practice, 5(2), 180-182.

17. Iriqat S, Yousef Q, Ereqat S. Clinical Profile of COVID-19 Patients Presenting with Uveitis - A Short Case Series. Int Med Case Rep J. 2021 Jun 23;14:421-427. doi: 10.2147/IMCRJ.S312461. PMID: 34188557; PMCID: PMC8236274
This work is licensed under Creative Commons Attribution 4.0 License

\section{To Submit Your Article Click Here: Submit Manuscript}

DOI:10.31579/2692-9392/078
Ready to submit your research? Choose Auctores and benefit from:

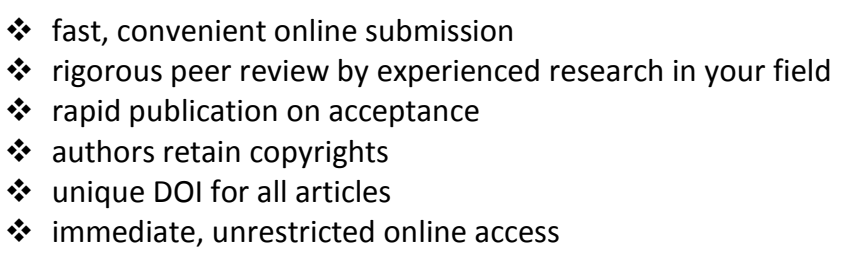

At Auctores, research is always in progress.

Learn more www.auctoresonline.org/journals/archives-of-medical-casereports-and-case-study 